\title{
Propagation Prediction of Mobile Networks at Buraidah Region via Different Frequencies and Terrain Profile
}

\author{
Anwar Hassan Ibrahim \\ Department of Electrical Engineering., College of Engineering, Qassim University, Qassim, Saudi Arabia, Buraidah \\ ORCID: 0000-0003-1771-6868
}

\begin{abstract}
Received Signal Strength Indicators (RSSI) is one of the main concerns in any wireless communication system deployment. Most of wireless infrastructure providing best connection for costumers as well as minimizing the wasted energy. This paper concentrated on major issues affect the signal disturbers in the area of study using well known empirical models to predict signal behaviours over different trainset profile in suburban area to obtain the best predicted model based on criteria caused by (RSSI). Stanford University Interim (SUI) and extended COST 231-Hata propagation models with actual measured data on different carrier frequencies has been considered for best prediction. The results show that the SUI propagation model gives the best performance according to the collected data in the area of study compared to the extended COST 231-Hata. The significant investigation in this paper confirmed by presenting the average signal in the path loss prediction.
\end{abstract}

Keywords: SUI model, COST 231-Hata model, Received Signal Strength Indicators (RSSI), signal loss.

\section{INTRODUCTION}

The probability and degrading of wireless applications are subject to signal strength drop or fluctuation which are common causes, due to environmental factors. The probability of proper received signal and corrupting of wireless applications are exposed to receive signal strength drop may case fluctuation during connection which are common causes in any wireless system, due to environmental factors [1][2][3][4]. All these applications connectivity and factors affect the network infrastructure and link performance [5]. A literature review in this chapter is conducted to report the current stage of work about the effect of propagation impairment in wireless PTP \& PTMP [6][7][8].

Due to the growing demand for outdoor wireless application, there must be a necessity for sufficient received signal strength according to propagation prediction for these wireless systems [9][10]. Since the wireless systems use wideband transmission, hence the quality of service has been extremely reliant on both average signal strength in an exact location and signal fading error [11].

\section{RELATED WORK}

A related background specifies in this paper reviewed the current stage of work done due to the effect of propagation impairment in wireless system. Wireless link has been widely installed in most of current communication system, hence the complexity of environment impairment requires to think about the terrain profile characterization to control the channel as the paired signal engagements inside the channel that may change during transmission processes [12][13]. In the same fact, researchers have done a few researches on empirical models relevant to the path loss estimation in mobile communication in addition to fixed wireless local area network organisations, such as Worldwide Interoperability for Microwave (WiMAX) [14]. A critical challenge on mobile communication is how to analyze the performance of these propagation impairment and evaluate the prediction which was always been a difficult part. Usually the signal from the transmitter follow more than one path to reaches the receiver, however it is affected by many channel factors in the environment surrounding the area, which will make the prediction much more complicated [15]. Several approaches of propagation prediction for outdoor link have been established, in both measurement accuracy and mathematical calculation [16].

\section{PATH-LOSS PREDICTION MODELS}

The case of signal path loss is basically caused by decreasing power spectral concentration of an electromagnetic as it is propagating through the build environment in which it is spreader. Several reasons occurs for the radio path loss according to the communication condition which may cause propagation prediction and link obtained accordingly [12].

Signals received by implies of tropospheric scramble appear both moderate and quick varieties. The moderate (slow) variations are fully depended on overall refractive situations in the atmosphere and the fast fading channel to the signal of small-scale indiscretions. The main differences between moderate and quick varieties are well defined by deliveries of the hourly median of signal transmission loss which are approximately stated in ITU report to suite for log-normal model with standard deviations between (4 and $8 \mathrm{~dB}$ ), liable to climate condition [17].

The signals travel over the terrain will have a significant effect on the signal specifications. Apparently, obstacles block the path will have much attenuation in the signal and frequently making reception problematic. Furthermore, at the low frequency the earth curvature will have more effect as well. The consequences of different parameters in wireless link association, such as distance from base stations and it is measured that path loss with distance increase from the transmitter due to a corresponding location in field strength [18].

\section{1) COST 231 Model}

Most of the famous model used for propagation predicting for path loss in communication system such as mobile wireless is the modified COST-231 Hata model. Essentially, it was established based on the Hata-Okumura model extension model. This purpose of this model is designed for the frequency range $(500-2000)$ MHz. The effortlessness and the obtainability of modified factors has improved usefulness of signal loss prediction at the path. This paper relies on frequency band of 700 and $900 \mathrm{MHz}$ based on the basic equation for propagation prediction in $\mathrm{dB}$ [1], [8], [19] $P L(d B)=\left(46.3+33.9 \log _{10}(f)-13.82 \log _{10}\left(h_{b}\right)-\right.$ $\left.a\left(h_{m}\right)+\left(44.9-6.55 \log _{10}\left(h_{b}\right)\right) \log _{10}(d)+C M\right)$ The parameter $\mathrm{A}(\mathrm{hm})$ is defined for urban environments as. $a\left(h_{m}\right)=2\left(\log _{10}(11.75 h r)\right) 2-4.97 \quad f>400 \mathrm{MHz}$ $a\left(h_{m}\right)=8.29\left(\log _{10}(1.54 h r)\right) 2-1.1 f \leq 400 \mathrm{MHz}$
and the equation for suburban environments, Where:

$$
a\left(h_{m}\right)=\left(1.1 \log _{10} f-0.7\right) h r-\left(1.56 \log _{10}-0.8\right)(4)
$$

$\mathrm{f}$ : measured frequency in $\mathrm{MHz}$ 
d: measured distance between Access Point and Customer Provided Equipment in $\mathrm{km}$.

$\mathrm{h}_{\mathrm{b}}$ : the antenna height for the access point in meters.

$\mathrm{CM}$ : measured with $0 \mathrm{~dB}$ for suburban and $3 \mathrm{~dB}$ for urban environments.

$\mathrm{h}_{\mathrm{r}}$ : The CPE antenna height above ground level.

\section{2) Stanford University Interim (SUI) Model}

SUI is an extension model of Hata, which was proposed as standards for high frequency bands below $11 \mathrm{GHz}$ cover the channel representations established by Stanford University, specifically stated the SUI models given as; [1],[8], [19]

$$
P L_{S U I}(d B)=A+10 \gamma \log _{10}\left(\frac{d}{d_{0}}\right)+X_{f}+X_{h}+S
$$

where, the distance (d) is measured between the Access point (AP) and the CPE in meters, $d_{0}=100 \mathrm{~m}$ and $S$ is a lognormally scattered factor, used the interpretation for the shadow fading due to the trees and other factors with the rate between $8.2 \mathrm{~dB}$ and $10.6 \mathrm{~dB}$. The additional parameters are well-defined as,

$$
\begin{aligned}
A & =20 \gamma \log _{10}\left(\frac{4 \pi d_{0}}{\lambda}\right) \\
\gamma & =a-b h_{b}+\left(\frac{c}{h_{b}}\right)
\end{aligned}
$$

where, the details of this parameters as follow;

$h_{b}$ considered as the base station height (BS) above the ground in meters and the range between $10 \mathrm{~m}$ and $80 \mathrm{~m}$.

The constants values for $\mathrm{a}, \mathrm{b}$ and $\mathrm{c}$ are assumed in table 1 and the $\gamma$ parameter in (equation no 7) is equal to the path loss exponent. For a given terrain type the path loss exponent is determined by $h_{b}$.

Table 1: The numerical values for the SUI model parameters

\begin{tabular}{|c|c|c|c|}
\hline Model Parameter & Terrain A & Terrain B & Terrain C \\
\hline$a$ & 3.7 & 3.3 & 4.1 \\
\hline$B(m-1)$ & 0.0068 & 0.0077 & 0.0058 \\
\hline$C(m)$ & 13 & 18.61 & 18.11 \\
\hline
\end{tabular}

The improvement for the selected operating frequency (700 and $900 \mathrm{Mhz}$ ) based on factors and the CPE antenna height are,

$$
\begin{gathered}
X_{f}=1.1 \log _{10}\left(\frac{f}{2000}\right) \\
X_{h}=-10.8 \log _{10}\left(\frac{h_{r}}{2000}\right)
\end{gathered}
$$

for Terrain types A and B

$$
X_{h}=-20 \log _{10}\left(\frac{h_{r}}{2000}\right)
$$

for Terrain type $\mathrm{C}$

where, frequency (f) measured in $\mathrm{MHz}$ and $\mathrm{h}_{\mathrm{r}}$ is the Customer Provided Equipment antenna height in meters. In this paper, the SUI model is considered to predict the path loss in entirely selected environments, namely suburban and urban [20], [21].

Due to the two models (COST-231 Hata model and SUI) integrated with measurement data have concentrated on these issues notified that, wireless communication has a strong potential prediction to improve the received signal indicators (RSSI). Although, the issues arrangement to propagation impairment during the wireless link assessment through wireless communication must take place in the performance due to the signal attenuation [22].

\section{SITE SELECTION AND CONSIDERATION}

The path profile and Site selections considered the most significant stage in the propagation prediction design of a wireless link. In most suitcases, an investigation of the path loss must confirm for suitable derive for the area of study. Characterization of the possible site selection is most necessary part [23], and the potential information on obstructions should be attained, and possible reflection may also be determined.

Furthermore figure (1) shows the link location at Buraidah site selection for study due to the frequent problems in the links.

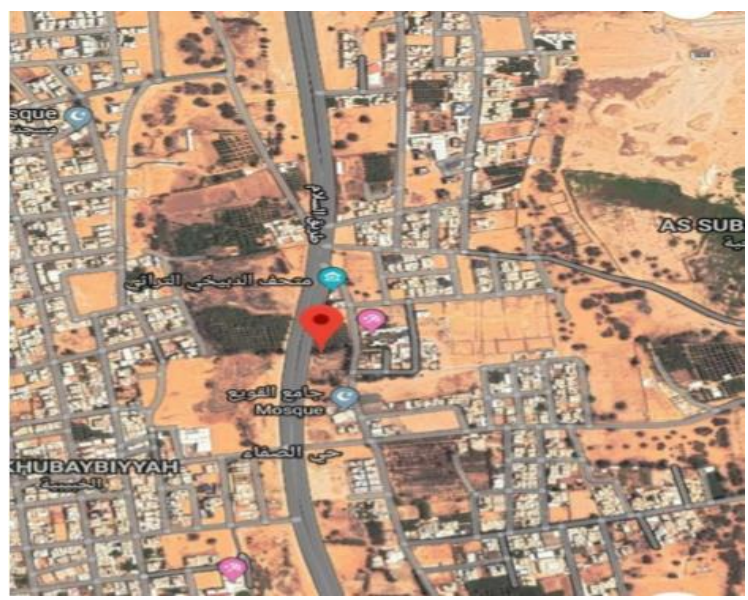

Fig 1. Google map:Site selection and link location at Buraidah

\section{METHODOLOGY}

The transmitted signal for all packets sent from the fixed base transceiver station link where specified by the index value and the received signal strength of all the packets received by the test bed computer are measured in terms of the received signal strength indicator (RSSI). Consecutively for these index values have index factors in measuring signal strength attenuation. Figure (2) represents the proposed details carried out on the element of data collection, measurements and selecting model. It contains a series of process in brief descriptive label describing the process being carried out on the data to generate the automatic system planning tools.

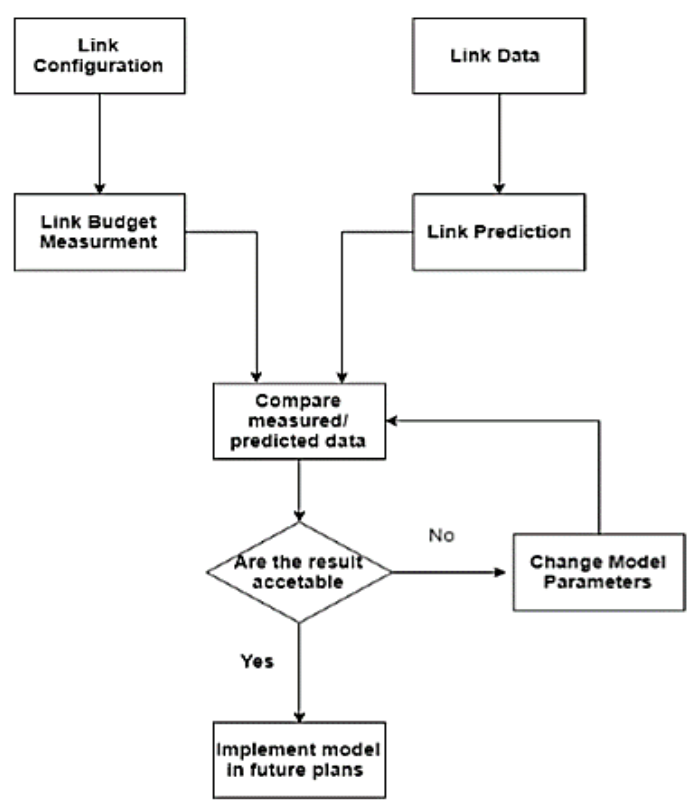

Fig 2. Flowcharts for the Proposed Method

\section{MEASUREMENT SETUP}

The received signal strength corresponding to each RSSI value will be determined by associate the values measured by the receiving test computer aid with known received signal strengths 
antenna associated with computer in verified distance as shown in figure (3).

The used equipment is i. Laptop (HP 320 core-i7): used to record data using TEMS 16.3 software. (shown in figure

GPS antenna (GLOBALSAT BU-353): connected with the laptop by USB port, used to measure the distance from the BTS as shown in figure 8 .

Cell phone (Huawei p10): used to detect the signal through wire interface with a Laptop device as shown in figure (3).

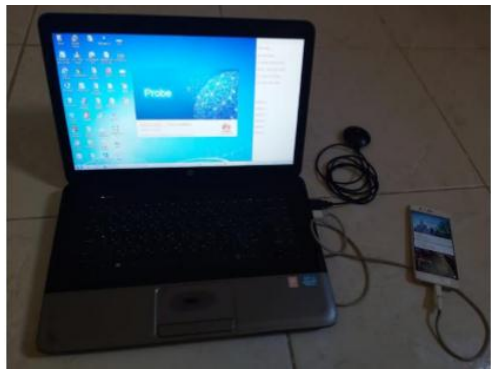

Fig 3. Measurements Setup

The main aim of link quality measurement training parameters is to get the best prediction values attained after the link configuration between locations.

\section{RESULTS AND DISCUSSION}

Before realizing any designs and verify the preparation of wireless connection arrangements, a precise propagation prediction and analysis of the environment of the area should be known. Data collection has been obtained, and presentation measurement issues were obtained. The key problem is that, to consider a well link optimization such as cell radius for base transceiver station (BTS) management systems, accurate information about the performance of the planning is needed. The reason for this is that by collecting the signal strength in the selected area, as accurate information about the link disturbance of the link between points can be known. The measurement is fully achieved and the performance of the selected link has been accurately determined.

The models that were investigated are based on SUI-Model and COST-231 Hata model, due to their popularity and applicability in the area of study, table 3 shows the input parameters for the measurement and models.

Table 3. Measurement parameters setup

\begin{tabular}{|c|c|c|}
\hline Constant & Symbol & Values \\
\hline BTS height & $H_{t}$ & 45 \\
\hline Receiver hight & $H_{r}$ & 2 \\
\hline Starting distance & $d_{0}$ & 100 \\
\hline
\end{tabular}

The COST-231 Hata model categorizes terrains into two groups, each type has different parameter values as shown in equations (2), (3) based on different frequencies. Both terrain parameters were applied and compared with the measured data, as shown in figure 4 at the frequency $900 \mathrm{MHz}$. based on the fitted data and two models applied to the same condition accordingly. This figure shows the close relevant of the model in case of urban and suburban area of the study. Figure 4 and 5 Shows the different between the most useful existing mathematical in urban and suburban area and empirical data that have been observed based on data measured from the given distance for frequency $(900 \mathrm{MHz})$ range for terrain A and terrain B in the area of study.

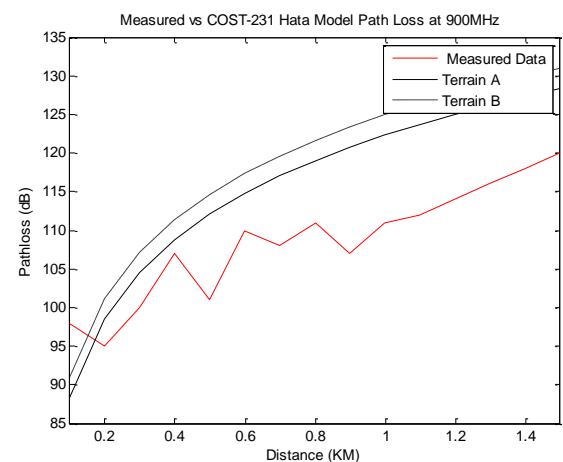

Fig 4. Measured Data vs COST-231 Hata model at the frequency $900 \mathrm{MHz}$

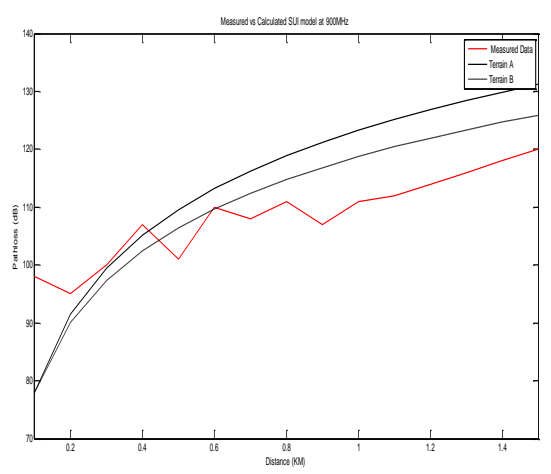

Fig 5. Measured Data vs SUI model at the frequency $900 \mathrm{MHz}$

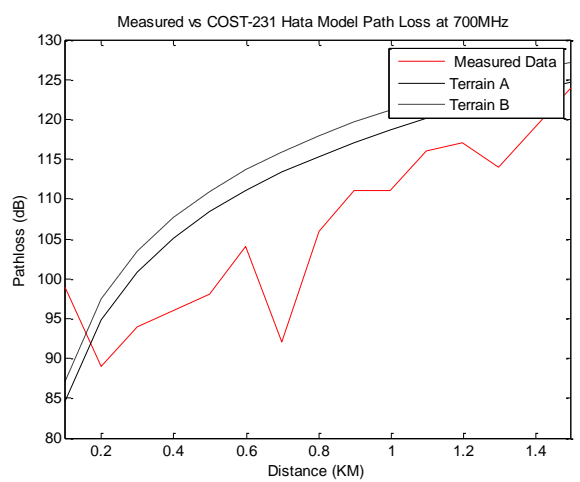

Fig 6. Measured vs COST-231 Hata model at the frequency $700 \mathrm{MHz}$

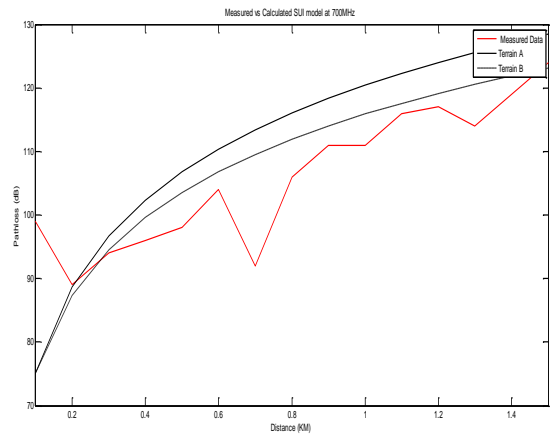

Fig 7. Measured vs SUI model at the frequency $900 \mathrm{MHz}$

Figure 6 and 7 Shows the different between the most useful existing mathematical in urban and suburban area and empirical 
data that have been observed based on data measured from the given distance for $700 \mathrm{MHz}$ frequency range.

\section{CONCLUSION}

In conclusion, this paper defines the path loss prediction models have been investigated. Two different path loss models for wireless mobile networks were tested, such as: extended COST231 Hata model and Stanford University Interim (SUI). The assessment is based on the signal path loss standards for the two models. To obtain the confirmation the results, the actual path loss is also computed through the measurements. After implementing different parameters for both SUI and COST 231-Hata models on different carrier frequencies $(700 \mathrm{MHz}$ and $900 \mathrm{MHz}$ ) and comparing it with the measured data, it has been concluded that SUI model gives more accurate perdition than COST 231Hata model in the area of study. Moreover, suggested in future planning in Buraidah, the SUI model should be implemented considering the city as a suburban area and use the terrain B parameters for the best RSSI prediction results.

\section{REFERENCES}

[1] Segun I.Popoola, Aderemi A.Atayero, and Oluwafunso A.Popoola. Comparative assessment of data obtained using empirical models for path loss predictions in a university campus environment. Journal of Data in Brief, Volume 18, June 2018, Pages 380-393.

[2] N. T. Surajudeen-Bakinde, N. Faruk, S. I. Popoola, M. A. Salman, A. A. Oloyede, and L. A. Olawoyin, "Path loss predictions for multitransmitter radio propagation in VHF bands using adaptive neuro-fuzzy inference system,' Eng. Sci. Technol., Int. J., vol. 21, no. 4, pp. 679-691, Aug. 2018.

[3] Aymen Zreikat and Milan Djordjevic. Performance Analysis of Path loss Prediction Models in Wireless Mobile Proceedings of the 3rd World Congress on Electrical Engineering and Computer Systems and Science (EECSS'17).

[4] H. K. Sharma, S. H. Sahu \& S. Sharma. "Enhanced cost 231 propagations model in wireless network", International journal of computer application, Vol. 19, No. 06, April 2011, pp. 0975 8887.

[5] Y. S. Kong, S. Abdullah, D. Schramm, M. Z. Omar, and S. M. Haris, "Optimization of spring fatigue life prediction model for vehicle ride using hybrid multi-layer perceptron artificial neural networks," Mech. Syst. Signal Process., vol. 122, pp. 597-621, May 2019.

[6] Bruno J. Cavalcanti, Gustavo A. Cavalcante, Laércio M. de Mendonça, Gabriel M. Cantanhede, Marcelo M.M. de Oliveira, Adaildo G. D'Assunção. A Hybrid Path Loss Prediction Model based on Artificial Neural Networks using Empirical Models for LTE And LTE-A at $800 \mathrm{MHz}$ and $2600 \mathrm{MHz}$. J. Microw. Optoelectron. Electromagn. Appl. vol.16 no.3 São Caetano do Sul Sept. 2017.Pp: 708-722.

[7] H. K. Hoomod, I. Al-Mejibli, and A. IssaJabboory 2017, "Optimizing SOM for cell towers distribution," in New Trends in Information \& Communications Technology Applications (NTICT), 2017 Annual Conference on, Baghdad, pp. 138-143.

[8] N.S Nkordeh, A.A.A Atayero, F.E Idachaba, O.O Oni. "LTE Network Planning using the Hata-Okumura and the COST-231 Hata Pathloss Models", Proceedings of the World Congress on Engineering 2014 Vol. 1, WCE 2014, July 2 - 4, London, U.K, 2014.

[9] Dalton Czane Gomes Valadaresa, Joseana Macdo Fechine Rgis de Arajoc, Marco Aurlio Spohnd, Angelo Perkusichb, Kyller Costa Gorgniob, Elmar Uwe Kurt Melcherc. 802.11g Signal Strength Evaluation in an Industrial Environment. Elsevier Internet of Things Journal. 2020. Pp:1-20.

[10] Haider Kadhim Hoomod, Intisar Al-Mejibli and Abbas Issa
Jabboory. Analyzing Study of Path loss Propagation Models in Wireless Communications at $0.8 \mathrm{GHz}$. IOP Conf. Series: Journal of Physics: Conf. Series 1003 (2018) 012028. Pp: 1-8.

[11] Dhouha El Houssaini, Sabrine Khriji, Kamel Besbes, and Olfa Kanoun. Performance Analysis of Received Signal Strength and Link Quality in Wireless Sensor Networks. 15th International Multi-Conference on Systems, Signals \& Devices (SSD), 2018. Pp: 1-5.

[12] K. A. Akpado, O. S. Oguejiofor, C. O. Ezeagwu, A. U. Okolibe, Investigating the Impacts of Base Station Antenna Height, Tilt and Transmitter Power on Network Coverage, International Journal of Engineering Science Invention, Vol. 2, No. 7, July. 2013, Pp. 3238.

[13] Ibhaze AE, Ajose SO, Atayero AA-A, Idachaba FE. Developing smart cities through optimal wireless mobile network. Proceedings of IEEE International Conference on Emerging Technologies and Innovative Business Practices for the Transformation of Societies (EmergiTech); 2016 Aug.p.118-23.

[14] T. Siva Priya, R. Mardeni. "Optimised COST-231 Hata Models for WiMAX Path Loss Prediction in Suburban and Open Urban Environments", Modern Applied Science,Vol. 4, No. 9, 2010, pp. 75-89.

[15] V. Dharmadhikari, N. Pusalkar, P. Ghare, Path loss exponent estimation for wireless sensor node positioning: Practical approach, in: 2018 IEEE International Conference on Advanced Networks and Telecommunications Systems (ANTS), 2018, pp. 1-4. doi:10.1109/ANTS.2018.8710123.

[16] M. Alhammadi, M. Almansoori, I. Tesfu, D. Habte, I. Ahmed, Large-scale empirical model for a $2.4 \mathrm{ghz}$ wireless network in an outdoor environment, in: 2019 Advances in Science and Engineering Technology International Conferences (ASET), 2019, pp. 1-4. doi:10.1109/ICASET.2019.8714201.

[17] Series of ITU-R Recommendations report (Recommendation ITU-R P.617-3). Propagation prediction techniques and data required for the design of trans-horizon radio-relay systems. (09/2013).

[18] Joseph Isabona, Chinule C Bright, Isaiah Gregory Peter. Radio Field Strength Propagation Data and Pathloss calculation Methods in UMTS Network. Advances in Physics Theories and Applications. Vol.21, 2013. Pp:54-68.

[19] Augustus Ehiremen Ibhaze, Agbotiname Lucky Imoize, Simeon Olumide Ajose, Samuel Ndueso John, Charles Uzoanya Ndujiuba and Francis Enejo Idachaba. An Empirical Propagation Model for Path Loss Prediction at $2100 \mathrm{MHz}$ in a Dense Urban Environment. Indian Journal of Science and Technology, Vol 10(5), DOI: 10.17485/ijst/2017/v10i5/90654, February 2017.

[20] Nasir Faruk, Segun I. Popoola, Nazmat T. Surajudeen-Bakinde, Abdulkarim A. Oloyede, Abubakar Abdulkarim , Lukman A. Olawoyin1, Maaruf Ali , Carlos T. Calafate, And Aderemi A. Atayero. Path Loss Predictions in the VHF and UHF Bands Within Urban Environments: Experimental Investigation of Empirical, Heuristics and Geospatial Models. IEEE access. Volume 7, 2019. Pp: 77293- 77307.

[21] H. K. Sharma, S. H. Sahu \& S. Sharma. "Enhanced cost 231 propagations model in wireless network", International journal of computer application, Vol. 19, No. 06, April 2011, pp. 0975 8887.

[22] Agbotiname Lucky Imoize, Augustus E. Ibhazeb, author Simeon O. Ajosed. Determination of Best-fit Propagation Models for Pathloss Prediction of a 4G LTE Network in Suburban and Urban Areas of Lagos, Nigeria. The West Indian Journal of Engineering Vol.41, No.2, January 2019, pp.13-21.

[23] M. D. Pereira, R. A. Romero, N. Fernandes, F. R. de Sousa, Pathloss and shadowing measurements at $2.4 \mathrm{ghz}$ in a power plant using a mesh network, in: 2018 IEEE International Instrumentation and Measurement Technology Conference (I2MTC), 2018, pp. 1-6. doi:10.1109/I2MTC.2018.8409563. 